\title{
Comparison of Intracranial Neuroendoscopic Procedures in Children versus Adults
}

\author{
Fady Girgis, Roberto Diaz, Walter Hader, Mark Hamilton
}

\begin{abstract}
Background: The emphasis regarding intracranial neuroendoscopy has been traditionally advocated and focused on the role in pediatric patients, although a significant usage has developed in adult patients. In this study, we examine and contrast the role of predominantly intracranial neuroendoscopy in both a pediatric and adult population with a minimum postprocedure follow-up of 5 years. Methods: A retrospective review was conducted for patients in the two hospitals that manage neurosurgical care for Southern Alberta, Canada, undergoing neuroendoscopic surgery between 1994 and 2008 . The pediatric group was defined as age $\leq 17$ years and the adult group as age $\geq 18$ years. Results: A total of 273 patients who underwent a total of 330 procedures with a mean postprocedure follow-up of 12.9 years were identified. There were 161 adult and 112 pediatric patients, and both groups underwent surgery by the same surgeons. The most common procedure was endoscopic third ventriculostomy, accounting for $55 \%$ of procedures. One postoperative death occurred in an adult patient. Endoscopic third ventriculostomy success 1-year postprocedure was $81 \%$, with only three late-term failures. Postoperative infection was the most common serious complication (two pediatric/four adult patients). Adult and pediatric patients had similar major complication rates $(4.2 \%$ vs $5.7 \%, \mathrm{p}=0.547)$. Conclusions: Neuroendoscopy overall had a similar role in both pediatric and adult neurosurgical populations, with the most commonly associated complication being infection. Neuroendoscopy is an important therapeutic modality in the management of appropriate adult patients.
\end{abstract}

RÉSUMÉ: Comparaison des interventions neuroendoscopiques intracrâniennes chez les enfants et chez les adultes. Contexte: Traditionnellement, l'emphase a été mise sur la neuroendoscopie intracrânienne chez les enfants et sur son rôle dans cette population de patients. Cependant, de telles interventions sont de plus en plus pratiquées chez des adultes. Nous examinons le rôle de la neuroendoscopie tant chez les enfants que chez les adultes et nous comparons son rôle dans ces deux populations de patients. Méthode: Nous avons procédé à une revue rétrospective des dossiers de patients ayant subi une chirurgie par neuroendoscopie entre 1994 et 2008 dans deux hôpitaux qui offrent des soins neurochirurgicaux dans la partie sud de l'Alberta, au Canada. Les patients du groupe pédiatrique étaient âgés de 17 ans ou moins et ceux du groupe adulte de 18 ans ou plus. Le suivi le plus court après l'intervention était de 5 ans. Résultats: Nous avons identifié 273 patients, dont 161 adultes et 112 enfants, qui ont subi au total 330 interventions, et chez qui un suivi moyen de 12,9 ans était disponible. Les deux groupes de patients ont été opérés par les mêmes chirurgiens. L'intervention la plus fréquemment effectuée était la ventriculostomie au niveau du 3 e ventricule, ce qui représentait $5 \%$ des interventions. Un patient adulte est décédé en période post-opératoire. La ventriculostomie du 3e ventricule par voie endoscopique s'est avéré un succès au moment du suivi 1 an après l'intervention chez $81 \%$ des patients. Trois échecs tardifs ont été rapportés. L'infection postopératoire était la complication sérieuse la plus fréquente, rapportée chez 2 enfants et 4 adultes respectivement. Les patients des deux groupes avaient les mêmes taux de complications majeures, soit 4,2\% chez les adultes et 5,7\% chez les enfants $(p=0,547)$. Conclusions: En général, la neuroendoscopie jouait un rôle similaire dans le traitement neurochirurgical des populations pédiatriques et adultes et l'infection était la complication la plus fréquente chez ces patients. La neuroendoscopie constitue donc également un moyen thérapeutique important dans le traitement de patients adultes.

Keywords: adult, complications, neuroendoscopy, pediatric

doi:10.1017/cjn.2015.287

Can J Neurol Sci. 2015; 42: 427-435

Neuroendoscopy is an important minimally invasive technique in neurosurgery ${ }^{1}$ and has evolved to include a role in both the diagnosis and treatment of a variety of disorders. ${ }^{2}$ In a historical context, the first therapeutic neuroendoscopic case was reported in Chicago in 1910, when L'Espinasse used a cystoscope to fulgurate the choroid plexus of two infants with hydrocephalus. ${ }^{3}$ Choroid plexus cauterization for the treatment of hydrocephalus gained popularity in the $1930 \mathrm{~s},{ }^{4}$ followed by endoscopic third ventriculoscopy (ETV) in the 1960s. ${ }^{5}$ However, it was not until the 1990s that endoscopy began to establish itself as a routine neurosurgical procedure. ${ }^{6}$ It grew from purely intraventricular applications to include surgery within other fluid-filled cavities such as the cisterna magna and the spinal canal, and eventually outside the cranial space to include skull base surgery, ${ }^{7}$ tumor biopsy and resection, exploration of the cerebellopontine angle,

From the Department of Neurosurgery, University of Calgary, Foothills Hospital, Calgary, Alberta, Canada (FG, RD, WH, MH).

Received December 6, 2014. Final Revisions Submitted June 9, 2015.

Correspondence to: Mark Hamilton, Professor of Neurosurgery, Department of Clinical

Neurosciences, University of Calgary, Foothills Medical Centre, 12th Floor, 1403,

29 St NW, Calgary, AB, T2N-2T9, Canada. Email: mghamilton.hydro@gmail.com. 
and treatment of craniosynostoses. ${ }^{8,9}$ Neuroendoscopy may be done via existing anatomical pathways (e.g. transnasal) or using transcortical single- or multiport systems, in addition to robotic applications. $^{10,11}$

As experience grows and techniques are refined, complication rates are decreasing and more and more neurosurgeons are enticed by the less-invasive appeal of the neuroendoscope. However, despite these advances and novel initiatives to train growing numbers of surgeons in the proper use of this technique, ${ }^{12,13}$ intracranial neuroendoscopy is still seen as a pediatric neurosurgery procedure, even though there are numerous indications in

Table 1: Adult endoscopic procedures and their major complications

\begin{tabular}{|c|c|c|c|c|}
\hline \multirow[b]{2}{*}{ Procedure } & \multirow[b]{2}{*}{$\begin{array}{c}\text { Number } \\
\text { performed }\end{array}$} & \multicolumn{3}{|c|}{ Type and number of major complication } \\
\hline & & Death & Meningitis & $\begin{array}{l}\text { Permanent neu- } \\
\text { rological deficit }\end{array}$ \\
\hline $\begin{array}{l}\text { Endoscopic third } \\
\text { ventriculostomy }\end{array}$ & 111 & & 4 & $\begin{array}{l}1^{*} \\
1^{\dagger}\end{array}$ \\
\hline Cyst fenestration & 16 & & & \\
\hline $\begin{array}{l}\text { Colloid cyst } \\
\text { decompression }\end{array}$ & 31 & & & \\
\hline $\begin{array}{l}\text { Tumor biopsy and/ } \\
\text { or resection }\end{array}$ & 20 & & & $1^{\ddagger}$ \\
\hline Septostomy & 6 & 1 & & \\
\hline $\begin{array}{l}\text { Endoscope-assisted } \\
\text { microsurgery }\end{array}$ & 3 & & & \\
\hline $\begin{array}{l}\text { Fenestration of } \\
\text { loculation }\end{array}$ & 2 & & & \\
\hline Total & 189 & 1 & 4 & 3 \\
\hline
\end{tabular}

*Cranial nerve palsy.

${ }^{\dagger}$ Chronic seizures.

${ }^{\ddagger}$ Hemiparesis. adult patients. We report a large series of neuroendoscopic cases in which the same surgeons performed both adult and pediatric procedures to illustrate the similarities and differences between pediatric and adult patient populations.

\section{MethodS}

Following institutional board approval (E-22666), a retrospective chart review was performed for all patients who underwent neuroendoscopic surgery at the Foothills Medical Centre and the Alberta Children's Hospital between 1994 and 2008, as identified from a patient-specific database. These two hospitals are tertiary care centers providing care to all neurosurgical patients in Southern Alberta and parts of South-Eastern British Columbia (population approximately 1.5 million). We excluded transnasal pituitary and skull base procedures.

Information was collected from operative reports, clinic notes, progress notes in hospital, and discharge summaries. Recorded data included patient demographics, presenting symptoms, procedures performed, complications, and follow-up times. Pediatric patients were defined as age $\leq 17$ years; adult patients were defined as age $\geq 18$ years. Major complications included death, permanent neurological deficit or endocrine abnormality, meningitis, and a subdural collection requiring shunting. Minor complications included cerebrospinal fluid (CSF) leak, seizure, wound infection, and transient neurological deficit or endocrine abnormality.

Statistical analysis was performed using the $\mathrm{R}$ programming environment (Vienna, Austria). A p value of less than 0.05 was predefined to indicate a statistically significant result.

\section{Results}

A total of 330 procedures were performed in 273 consecutive patients between 1994 and 2008; these comprised 141 procedures in 112 pediatric patients and 189 procedures in 161 adult patients. Both adult and pediatric cases were performed by the same

Table 2: Pediatric endoscopic procedures and their major complications

\begin{tabular}{|c|c|c|c|c|c|}
\hline \multirow[b]{2}{*}{ Procedure } & \multirow[b]{2}{*}{$\begin{array}{c}\text { Number } \\
\text { performed }\end{array}$} & \multicolumn{4}{|c|}{ Type and number of major complication } \\
\hline & & Meningitis & $\begin{array}{l}\text { Permanent endocrine } \\
\text { abnormality }\end{array}$ & $\begin{array}{c}\text { Permanent neurological } \\
\text { deficit }\end{array}$ & $\begin{array}{l}\text { Subdural collection requiring } \\
\text { shunting }\end{array}$ \\
\hline $\begin{array}{l}\text { Endoscopic third } \\
\text { ventriculostomy }\end{array}$ & 71 & 2 & $1^{*}$ & $1^{\dagger}$ & \\
\hline Cyst fenestration & 37 & & $\begin{array}{l}1^{\ddagger} \\
1 *\end{array}$ & & 2 \\
\hline Septostomy & 9 & & & & \\
\hline $\begin{array}{l}\text { Endoscope-assisted } \\
\text { microsurgery }\end{array}$ & 8 & & & & \\
\hline Tumor biopsy and/or resection & 7 & & & & \\
\hline Fenestration of loculation & 4 & & & & \\
\hline Spinal cord detethering & 4 & & & & \\
\hline Colloid cyst decompression & 1 & & & & \\
\hline Total & 141 & 2 & 3 & 1 & 2 \\
\hline
\end{tabular}

*Obesity.

${ }^{\dagger}$ Memory deficit.

${ }^{\ddagger}$ Panhypopituitarism. 
surgeons. ETV was the most common procedure performed in both groups. As expected from disease presentations and characteristics, more colloid cysts were resected in adults and more arachnoid cysts were fenestrated in children. Mean followup duration after the neuroendoscopic procedure was 12.9 years (range 5.7-19.7 years excluding one early death) and median follow-up 12.8 years.

A breakdown of the adult procedures and their complications is shown in Table 1. As seen in the table, ETV was the most common procedure performed in adult patients, followed by colloid cyst resection, tumor biopsy, and cyst fenestration. Major complications occurred in eight of 189 procedures, giving a major complication rate of $4.23 \%$. These included four cases of meningitis and three cases of permanent neurological deficit, which included one postoperative case of hemiparesis, one cranial nerve palsy, and one patient who developed chronic seizures. In addition, one death occurred following septostomy in a 55-year-old man with a ventriculoperitoneal shunt. His shunt failed because of ventriculitis and a cerebellar abscess, and following the urgent removal of the shunt, a septostomy, and placement of an extraventricular drain, he developed a large intracerebral hemorrhage around the drain. Given his overall poor state, care was withdrawn.
A breakdown of the pediatric procedures and their complications is shown in Table 2. As seen in the table, ETV was the most common procedure performed in pediatric patients, followed by cyst fenestration. Major complications occurred in eight of 141 procedures, giving a major complication rate of $5.67 \%$. These included two cases of meningitis, two patients who developed permanent and severe weight gain, one patient with panhypopituitarism, one patient with severe memory impairment, and two patients who developed subdural collections that required shunting.

A breakdown of all minor complications in both pediatric and adult patients is shown in Table 3. Minor complications occurred in 27 of 330 total procedures, giving an overall minor complication rate of $8.18 \%$. The most common of these were CSF leak and transient seizures, followed by wound infection, transient weight gain or electrolyte abnormality, and transient cranial nerve III palsy.

We have previously reported the success of ETV to treat hydrocephalus as defined by remaining shunt-free at 1 year postprocedure ${ }^{14}$ with rates of $82.5 \%$ for primary ETV and $82 \%$ for ETV done in the setting of shunt failure and subsequent shunt removal. The success rate for this expanded population is essentially unchanged $(81 \%)$, and only three delayed failures of ETV

Table 3: Minor complications of all procedures

\begin{tabular}{|c|c|c|c|c|c|c|c|}
\hline \multirow[b]{2}{*}{ Procedure } & \multirow{2}{*}{$\begin{array}{c}\text { Number of procedures (adult } \\
\text { and pediatric) }\end{array}$} & \multicolumn{6}{|c|}{ Number of minor complications } \\
\hline & & $\begin{array}{l}\text { CSF } \\
\text { leak }\end{array}$ & Seizure & $\begin{array}{l}\text { Wound } \\
\text { infection }\end{array}$ & $\begin{array}{c}\text { Transient } \\
\text { weight gain }\end{array}$ & $\begin{array}{c}\text { Transient electrolyte } \\
\text { abnormality }\end{array}$ & $\begin{array}{c}\text { Transient } \\
\text { neurological deficit }\end{array}$ \\
\hline $\begin{array}{l}\text { Endoscopic third } \\
\text { ventriculostomy }\end{array}$ & 182 & 4 & 3 & 2 & 4 & 2 & $3 *$ \\
\hline Cyst fenestration & 53 & 2 & 2 & 1 & & 1 & \\
\hline Colloid cyst & 32 & & 1 & & & & $1^{\dagger}$ \\
\hline Tumor biopsy/resection & 27 & & & & & & \\
\hline Septostomy & 15 & & & & & & \\
\hline $\begin{array}{l}\text { Endoscope-assisted } \\
\text { microsurgery }\end{array}$ & 11 & & & & & & \\
\hline Other ${ }^{\ddagger}$ & 10 & & & 1 & & & \\
\hline Total & 330 & 6 & 6 & 4 & 4 & 3 & 4 \\
\hline
\end{tabular}

*Cranial nerve III palsy.

${ }^{\dagger}$ Hemiparesis.

${ }^{\ddagger}$ Includes four spine detetherings and six fenestrations of loculation.

Table 4: Differences in major complication rates by procedure

\begin{tabular}{l|c|c|c}
\hline Procedure & Adult & Pediatric & p value \\
\hline Cyst fenestration & $0 \%(0 / 16)$ & $10.8 \%(4 / 37)$ & 0.171 \\
\hline Septostomy & $16.7 \%(1 / 6)$ & $0 \%(0 / 9)$ & 0.205 \\
\hline Tumor biopsy and/or resection & $5.0 \%(1 / 20)$ & $0 \%(0 / 7)$ & 0.547 \\
\hline Endoscopic third ventriculostomy & $5.4 \%(6 / 111)$ & $5.6 \%(4 / 71)$ & 0.947 \\
\hline Colloid cyst decompression & $0 \%(0 / 31)$ & $0 \%(0 / 1)$ & N/A \\
\hline Endoscope-assisted microsurgery & $0 \%(0 / 3)$ & $0 \%(0 / 8)$ & N/A \\
\hline Total & $4.2 \%(8 / 189)$ & $5.7 \%(8 / 141)$ & 0.547 \\
\hline
\end{tabular}

Incidence of major complication rates (number of major complications per total number of procedures) in endoscopic procedures for adult versus pediatric patients. The $\mathrm{p}$ values calculated using two-tailed chi-square test (alpha $=0.05)$. 
have occurred with long-term follow-up. All three delayed failures occurred in patients who underwent their ETV when younger than age 18 . Two occurred within 2 years and one 10 years post-ETV as an adult. All underwent successful repeat ETV procedures and remain shunt-free.

To determine if there was a difference in the incidence of complications between adult and pediatric patients undergoing specific neuroendoscopic procedures, two-tailed chi-square tests were applied to major complication rates for each type of procedure, but none reached statistical significance (Table 4), nor did the overall complication rate between adult and pediatric patients (4.2\% vs $5.7 \%, \mathrm{p}=0.547)$.

Univariate logistic regression analysis was used to attempt to identify any specific procedures that may potentially be associated with major complications, and to determine if there was a relation between patient age and complication rates, but neither reached statistical significance (odds ratios, 0.62-1.43; p values, 0.22-0.79).

\section{Discussion}

As minimally invasive approaches grow in popularity, endoscopy is becoming a powerful tool in the neurosurgeon's armamentarium. ${ }^{15}$ However, despite the appeal of a smaller incision, and the now well-described anatomy of intraventricular spaces, ${ }^{16,17}$ serious perioperative complications may occur. This is largely due to the proximity of the endoscope to critical neural structures, as is the case in several endoscopic procedures. ${ }^{18,19}$ However, the incidence of complications is low, as reported in our population-based study, and varies with operative indication as well as patient age. Despite our finding that there is no statistically significant difference in complication rates between adult and pediatric patients, neuroendoscopy maintains the reputation of being a largely pediatric technique.

This large study is the first, to our knowledge, to report on endoscopic cases wherein the same surgeons performed both the pediatric and adult procedures, allowing for a direct and meaningful comparison of complication rates between the two patient groups. It is also the first to provide significant long-term follow-up.

Here we discuss the complications and outcomes of neuroendoscopy through its currently established indications.

\section{Hydrocephalus}

Hydrocephalus is a heterogeneous group of disorders that spans a wide range of ages and symptom profiles. ${ }^{20}$ As such, each patient requires an individualized diagnostic and treatment approach. Traditionally, the treatment of hydrocephalus involved ventricular shunting, but because of the tendency of those systems to fail over time, whether from shunt malfunction or infection, ${ }^{21}$ endoscopic techniques are emerging as possible alternatives. These include ETV and septostomy, options that are most suitable for treating those patients with obstructive hydrocephalus. ${ }^{20-30}$ ETV consists of creating a hole through the tuber cinereum in the floor of the third ventricle to allow CSF to flow into the interpeduncular and prepontine cisterns, thereby bypassing obstructions in the aqueductal area, ${ }^{21,31-40}$ whereas septostomy involves placing the hole in the septum pellucidum. Another postulated mechanism involves the restoration of the pulsatility of ventricular walls as a result of the stoma, an effect that may help restore CSF dynamics by driving CSF flow from the ventricular system into the subarachnoid space. ${ }^{22}$ On occasion, both ETV and septostomy may be required for the same patient to treat hydrocephalus.

The overall success rate of ETV has been reported as high as $89 \%,{ }^{23}$ and possibly even higher in the subset of patients with aqueductal stenosis, ${ }^{41}$ with most failures presenting in the first few weeks after surgery. ${ }^{24}$ The long-term success for ETV in this pediatric and adult patient population was $81 \%$. Various classification systems are emerging not only to help predict outcome after endoscopic procedures for hydrocephalus, but also to aid in the selection of appropriate patients to maximize positive outcomes. $^{25,42-45}$

The most common indication for ETV is aqueductal stenosis, either from congenital narrowing of the aqueduct or obstructive tumors such as tectal gliomas ${ }^{46}$ and obstructive cysts. ${ }^{47,48}$ Other indications include the fenestration of loculated compartments, ${ }^{49,50}$ ventriculoperitoneal shunt malfunction, ${ }^{26,27}$ and preresectional ETV for posterior fossa tumors. ${ }^{51}$ Yet another potential role for ETV is in the realm of communicating hydrocephalus ${ }^{52}$ - specifically normal pressure hydrocephalus $^{53,54}$ _although these remain controversial indications. A recent randomized, open-label trial of 42 patients with normal pressure hydrocephalus found that those treated with a ventriculoperitoneal shunt had significantly better neurological outcomes at 12 months compared with those who underwent ETV (77\% vs 50\%), ${ }^{55}$ whereas a large population-based study using institutional data found that ETV is associated with greater perioperative mortality and complication rates in these patients compared with shunting. ${ }^{56}$ Although more needs to be learned about this patient population, and the benefits of ETV seem inferior to shunting in hydrocephalic people with normal or low pressures, it may still play a role in appropriately selected patients. ${ }^{57}$

Appropriate candidates for ETV include both adults and children, although infants younger than 1 year old tend to have worse outcomes, ${ }^{23,58-62}$ especially if they are born preterm or with a low birth weight. ${ }^{63}$ Our series only had 34 children younger than 1 year of age undergoing a neuroendoscopic procedure, and only 14 underwent ETV. Complication rates in our pediatric population differed slightly from the literature in that, whereas overall trends showed complication rates increased with decreasing age, the highest rates of complication occurred in the 5- to 10-year-old age range.

In our series, 182 third ventriculostomies and 15 septostomies were performed; of these 197 procedures, 80 were performed on pediatric patients and 117 on adult patients. The overall major complication rate was $5.6 \%$, which is similar to that of other studies. A recent systematic review by Bouras and Sgouros examined 2985 ETV procedures and reported an overall complication rate of $8.5 \%$, a permanent morbidity rate of $2.4 \%$, and a mortality rate of $0.21 \% .^{64}$ Jenkinson reported a $5.8 \%$ complication rate in 190 adult ETV procedures ${ }^{65}$ and Kadiran described a $4.9 \%$ infection rate, $7.2 \%$ transient major complication rate, and a $1.1 \%$ permanent complication rate in 203 ETV patients. ${ }^{23}$ In general, it has been reported that complication and mortality rates decrease with increased surgeon experience and are lower compared with open procedures in experienced hands. ${ }^{47,66,67}$ A qualitative analysis of our study did show that complication rates marginally decreased as surgeon experience increased, but it is important to note that equipment quality also improved over the course of the 
series. There were also more adult cases done later in the series, which may have contributed to the lower, albeit nonsignificant, complication rate in adult versus pediatric patients (4.2\% vs $5.7 \%)$.

In addition, complications have been reported to occur more frequently in previously shunted patients than in patients treated for newly diagnosed hydrocephalus ${ }^{14}$ as well as patients undergoing repeat procedures. ${ }^{14,68}$ However, many of these complications are classified as minor, are transient, and may not affect long-term outcome. Therefore, when assessing the risks versus benefits of performing ETV in previously shunted patients, it is important to take into consideration the natural history of these patients when using a shunt, and subsequently their cumulative risk of shunt revision and infection over the lifespan of the shunt.

Overall, the complication rate for ETV is low and is similar to the expected infection rate associated with shunts. ${ }^{14}$ Although the potential exposure to significant neurological complications with ETV may be higher than the risk of a single shunt operation, the possibility of achieving long-term shunt independence with ETV should be considered preferable in good-risk patients when compared with the cumulative morbidity of multiple shunt procedures. ${ }^{67}$ Absolute contraindications to ETV include small ventricular size preventing safe intraventricular manipulation of the scope and a tumor obstructing the surgeon's access to the floor of the third ventricle. ${ }^{69}$ These scenarios aside, the difficulties inherent to pediatric endoscopy and the risks associated with more complex cases may be alleviated with the use of neuronavigation, a technique that has been shown to a safe and beneficial adjunct to endoscopy. ${ }^{70-72}$ Several systems, such as AxiEM (Medtronic, USA) currently used at our center, allow frameless navigation of the endoscope in patients that are unable to safely undergo rigid cranial fixation in pins because of young age or thin skull vaults, and in the subset of patients who have complicated or distorted ventricular anatomy. ${ }^{70,73}$

\section{Tumors}

Endoscopic tumor management is a safe and effective alternative to conventional means and allows the option of ETV or septostomy for treatment of associated hydrocephalus. ${ }^{74-90}$ The results in most series are based on data from both adult and pediatric populations. Neuroendoscopy in the field of neurooncology offers the advantages of improved visualization of intraventricular pathology, better management of tumor-related hydrocephalus, less morbid biopsies, and the allowance of minimally invasive removal of intraventricular tumors. ${ }^{77,91}$ Certain characteristics make a tumor ideally suited for endoscopic biopsy or resection. ${ }^{78}$ These include moderate to low vascularity, soft-consistency, tumors smaller than $2 \mathrm{~cm}$ in diameter, those associated with secondary hydrocephalus, those that are histologically low grade, and lesions situated in the lateral ventricle and pineal region. ${ }^{76,92}$ In addition, tumors that will be treated primarily nonsurgically, such as gliomas of the tectal region, are ideally suited for primary treatment of obstructive hydrocephalus and, if appropriate, neuroendoscopic biopsy. ${ }^{77}$

In our series, 27 intraventricular tumors were biopsied, four of which were also resected. Of the 27 patients, there were 20 adults and seven pediatric patients. The overall major complication rate was $3.7 \%$, which is consistent with that of other series. Constantini et al reported a large series of 293 patients who underwent endoscopic tumor biopsy with an infection rate of $3 \%$ and a mortality rate of $0.3 \% .^{93}$ Another report by Luther et al of 86 intraventricular tumors that were biopsied or resected had a hemorrhagic sequelae rate of $3.5 \% .^{79}$ They defined clinically significant hemorrhage as that resulting in abandonment of the procedure, postoperative hydrocephalus requiring shunting, neurological change, or hemorrhage that required a second procedure to treat the bleed. In addition, Tirakotai et al described 46 patients (mean age 43.8 years) with peri- and intraventricular tumors who underwent neuroendoscopic procedures with three transient morbidities and one permanent deficit, but no operative mortality. ${ }^{81}$

\section{Arachnoid Cysts}

Primary arachnoid cysts are developmental lesions containing a fluid similar to CSF and are often incidentally found in patients as a focal area of fluid accumulation with bulging and thinning of the adjacent skull. ${ }^{94}$ Overall, arachnoid cysts account for approximately $1 \%$ of all intracranial mass lesions, with potentially up to $60-90 \%$ of these becoming symptomatic in childhood. ${ }^{95}$ Patients presenting with symptoms or signs of increased intracranial pressure or seizures and with growing arachnoid cysts are typically considered for surgical treatment. Endoscopic surgery has become the treatment of choice when feasible because of its minimal invasiveness and good outcomes. ${ }^{95-105}$ Assessment of the anatomical relationship between the arachnoid cyst wall and adjacent anatomical structures such as blood vessels, cranial nerves, and brain parenchyma is necessary during preoperative planning to avoid injury to these structures. Complications may include intraoperative bleeding obscuring the surgeon's visual field, postoperative subdural hematomas or hygromas, meningitis, or the injuring of adjacent structures during fenestration. ${ }^{106}$

In our combined series, 53 cyst fenestrations were performed, 16 in adults and 37 in pediatric patients. The overall major complication rate was $7.5 \%$, which is similar to that of other series. For example, Nowoslawska et al reviewed 106 children with arachnoid cysts, 44 of whom underwent a neuroendoscopic procedure and 62 of whom underwent other operations. ${ }^{101}$ Eleven of the 44 experienced complications, including five CSF leaks, two third nerve palsies, two subdural hematomas, one case of meningitis, and one case of severe intraoperative bleeding. In the nonendoscopic group, there were ten with complications. In a smaller series reported by Huang et al of 15 patients who underwent neuroendoscopic arachnoid cyst fenestration, there was only one complication of chronic subdural hematoma that was treated with burr hole drainage. ${ }^{100}$ The authors concluded that, compared with traditional treatments, neuroendoscopic cystic fenestration is more effective and minimally invasive with less mortality and morbidity. Similarly, two additional patient series, one reported by Schroeder et al of 21 endoscopically fenestrated arachnoid cysts revealed no deaths or permanent complications ${ }^{102}$; another study by Pradilla et al of 11 endoscopically treated arachnoid cysts (mean age 10.9 years) found one patient left with persistent spasticity and one patient suffering mild hemiparesis. ${ }^{95}$ These authors concluded that cyst fenestration is favored over shunting as the method of choice for initial cyst decompression.

\section{Colloid Cysts}

Colloid cysts are benign space-occupying lesions that typically arise in the region of the anterior third ventricle ${ }^{107}$ and represent about $0.5-2 \%$ of intracranial tumors. ${ }^{108}$ Although uncommon, 
they are an important clinical entity because of their ability to cause CSF obstruction at the foramina of Munro with resultant hydrocephalus, which in the acute state can lead to sudden death. ${ }^{108}$ If the obstruction of the foramina of Monro is asymmetrical, one lateral ventricle can grow larger than the other, resulting in bowing of the septum pellucidum to the nonaffected side. ${ }^{109}$ Although microsurgery has been the classic treatment option, ${ }^{110}$ the composition and location of these cysts make them ideally suited for endoscopic excision. ${ }^{111-115}$ Expectedly, the success of endoscopic colloid cyst removal is heavily dependent upon the surgeon's experience. ${ }^{77}$

In our series, 32 colloid cysts were endoscopically resected, 31 of which were in adult patients. The overall major complication rate was $3.1 \%$, and the cyst recurred in one case. We have previously presented our data in comparison to microsurgical resections, showing that endoscopic resection of colloid cysts can be performed with a significantly lower risk of complications than microsurgical resection (4\% vs $33 \%$ ), and with equivalent surgical success. ${ }^{108}$ In addition, operative time and length of hospital stay are both significantly reduced with endoscopic resection. Similar results were found in a series of 30 patients reported by Lewis et al, ${ }^{116}$ where half underwent open resection and the other half endoscopic resection of a colloid cyst. They found the endoscopic group had shorter hospital stay and operative time, as well as a shorter interval before returning to work. Similarly, Longatti et al reported on 61 patients (mean age 41 years) undergoing endoscopic colloid cyst resection who had a complication rate of $3.2 \%$, with seven asymptomatic recurrences, ${ }^{110}$ and Greenlee et al reported 35 patients (mean age 32.4 years) experiencing a complication rate of $8.6 \% .^{117}$

\section{Summary AND CONCluSIONS}

Intracranial, intraventricular neuroendoscopy was performed in 161 adult and 112 pediatric patients. A higher percentage of pediatric patients underwent cyst fenestration, whereas a higher percentage of adults underwent ETV, colloid cyst removal, and tumor biopsy. The most common complication associated with neuroendoscopy was infection, and adult and pediatric patients had similar complication rates. These findings highlight the important potential role for neuroendoscopy during management of appropriate adult patients. Therefore, neuroendoscopy should be an available therapeutic modality in all neurosurgical centers and should be considered as a potential therapeutic modality in the management of suitable adult as well as pediatric patients.

\section{DisClosures}

All authors have seen and approved this manuscript and have no disclosures to report. No portion of this work has been previously published or presented. FG, RD, WH, and $\mathrm{MH}$ declare they have no conflict of interest.

\section{REFERENCES}

1. Grunert P, Gaab MR, Hellwig D. Oertel JMK. German neuroendoscopy above the skull base. Neurosurgical Focus. 2009 Sep;27(3):E7.

2. Cappabianca P, Cinalli G, Gangemi M, et al. Application of neuroendoscopy to intraventricular lesions. Neurosurgery. 2008 Feb;62 Suppl 2:575-97; discussion 97-8.

3. Abbott R. History of neuroendoscopy. Neurosurgery Clinics of North America. 2004 Jan;15(1):1-7.

4. Harris LW. Endoscopic techniques in neurosurgery. Microsurgery. 1994;15(8):541-6.
5. Enchev Y, Oi S. Historical trends of neuroendoscopic surgical techniques in the treatment of hydrocephalus. Neurosurgical Review. 2008 Jul;31(3):249-62.

6. Di Rocco C, Cinalli G, Massimi L, Spennato P, Cianciulli E, Tamburrini G. Endoscopic third ventriculostomy in the treatment of hydrocephalus in pediatric patients. Advances \& Technical Standards in Neurosurgery. 2006;31:119-219.

7. Chrastina J, Novak Z, Riha I. Neuroendoscopy. Bratislavske Lekarske Listy. 2008;109(5):198-201.

8. Van Rompaey J, Bush C, McKinnon B, Solares A. EMinimally invasive access to the posterior cranial fossa: an anatomical study comparing a retrosigmoidal endoscopic approach to a microscopic approach. Journal of Neurological Surgery. 2013 Jan;74(1):1-6.

9. Jenkins G, Smith N, McNeely P. Pancraniosynostosis following endoscope-assisted strip craniectomy and helmet orthosis for sagittal suture craniosynostosis in a nonsyndromic patient. Journal of Neurosurgery, Pediatrics. 2013 Jul;12(1):77-9.

10. Vogel TW, Manjila S, Cohen AR. Cranial neuroendoscopy: novel applications and next frontiers. Journal of Neurosurgical Sciences. 2011 Sep;55(3):243-57.

11. Zada G, Liu C. Apuzzo MLJ. "Through the looking glass": optical physics, issues, and the evolution of neuroendoscopy. World Neurosurgery. 2013 Feb;79(2 Suppl):S3-13.

12. Agrawal A, Kato Y, Sano H, Kanno T. The incorporation of neuroendoscopy in neurosurgical training programs. World Neurosurgery. 2013 Feb;79(2 Suppl):S15.e1-3.

13. Filho FVG, Coelho G, Cavalheiro S, Lyra M, Zymberg ST. Quality assessment of a new surgical simulator for neuroendoscopic training. Neurosurgical Focus. 2011 Apr;30(4):E17.

14. Hader WJ, Walker RL, Myles ST, Hamilton M. Complications of endoscopic third ventriculostomy in previously shunted patients. Neurosurgery. 2008 Jul;63(1 Suppl 1):ONS168-74; discussion ONS74-5.

15. Hardavella G, Ianovici N. Current trends in minimally invasive neurosurgery: neuro-endoscopy. Revista Medico-Chirurgicala a Societatii de Medici Si Naturalisti Din Iasi. 2005 Jul-Sep; 109 (3):528-31.

16. Longatti P, Fiorindi A, Feletti A, D'Avella D, Martinuzzi A. Endoscopic anatomy of the fourth ventricle. Journal of Neurosurgery. 2008 Sep;109(3):530-5.

17. Longatti P, Fiorindi A, Perin A, Martinuzzi A. Endoscopic anatomy of the cerebral aqueduct. Neurosurgery. 2007 Sep;61(3 Suppl): 1-5; discussion 6.

18. Cinalli G, Spennato P, Ruggiero C, et al. Complications following endoscopic intracranial procedures in children. Childs Nervous System. 2007 Jun;23(6):633-44.

19. Ganjoo P, Sethi S, Tandon MS, Singh D, Pandey BC. Perioperative complications of intraventricular neuroendoscopy: a 7-year experience. Turkish Neurosurgery. 2010 Jan; 20(1):33-8.

20. Bergsneider M, Miller C, Vespa PM, Hu X. Surgical management of adult hydrocephalus. Neurosurgery. 2008 Feb;62(Suppl 2): 643-59; discussion 59-60.

21. Jallo GI, Kothbauer KF, Abbott IR. Endoscopic third ventriculostomy. Neurosurgical Focus. 2005 Dec 15;19(6):E11.

22. Gangemi M, Maiuri F, Colella G, Magro F, Seneca V, de Divitiis E. Is endoscopic third ventriculostomy an internal shunt alone? Minimally Invasive Neurosurgery. 2007 Feb;50(1):47-50.

23. Kadrian D, van Gelder J, Florida D, et al. Long-term reliability of endoscopic third ventriculostomy. [Reprint in Neurosurgery. 2008 Feb;62 Suppl 2:614-21; PMID: 18596443]. Neurosurgery. 2005 Jun;56(6):1271-8; discussion 8.

24. Santamarta D, Diaz Alvarez A, Goncalves GM, et al. Outcome of endoscopic third ventriculostomy. Results from an unselected series with noncommunicating hydrocephalus. Acta Neurochirurgica. 2005 Apr;147(4):377-82; discussion 82.

25. Kulkarni AV, Drake JM, Mallucci CL, et al. Endoscopic third ventriculostomy in the treatment of childhood hydrocephalus. Journal of Pediatrics. 2009 Aug;155(2):254-9. e1.

26. Bilginer B, Oguz KK, Akalan N. Endoscopic third ventriculostomy for malfunction in previously shunted infants. Childs Nervous System. 2009 Jun;25(6):683-8.

27. O'Brien DF, Javadpour M, Collins DR, Spennato P, Mallucci CL. Endoscopic third ventriculostomy: an outcome analysis of 
primary cases and procedures performed after ventriculoperitoneal shunt malfunction. Journal of Neurosurgery. 2005 Nov;103(5 Suppl):393-400.

28. Bouramas D, Paidakakos N, Sotiriou F, Kouzounias K, Sklavounou M, Gekas N. Endoscopic third ventriculostomy in obstructive hydrocephalus: surgical technique and pitfalls. Acta Neurochirurgica - Supplement. 2012;113:135-9.

29. Teo C, Kadrian D, Hayhurst C. Endoscopic management of complex hydrocephalus. World Neurosurgery. 2013 Feb;79(2 Suppl): S21.e1-7.

30. Vogel TW, Bahuleyan B, Robinson S, Cohen AR. The role of endoscopic third ventriculostomy in the treatment of hydrocephalus. Journal of Neurosurgery Pediatrics. 2013 Jul;12 (1):54-61.

31. Hellwig D, Grotenhuis JA, Tirakotai W, et al. Endoscopic third ventriculostomy for obstructive hydrocephalus. Neurosurgical Review. 2005 Jan;28(1):1-34; discussion 5-8.

32. Naftel RP, Tubbs RS, Reed GT, Wellons JC 3rd. Small ventricular access prior to rigid neuroendoscopy. Journal of Neurosurgery. 2010 Oct;Pediatrics, 6(4):325-8.

33. Ebner FH, Marquardt JS, Hirt B, Feigl GC, Tatagiba M, Schuhmann MU. Broadening horizons of neuroendoscopy with a variable-view rigid endoscope: an anatomical study. European Journal of Surgical Oncology. 2010 Feb;36(2):195-200.

34. van Beijnum J, Hanlo PW, Fischer K, et al. Laser-assisted endoscopic third ventriculostomy: long-term results in a series of 202 patients. Neurosurgery. 2008 Feb;62(2):437-43; discussion 43-4.

35. Costa Val JA. Minicraniotomy for endoscopic third ventriculostomy in babies: technical note with a 7-year-segment analysis. Childs Nervous System. 2009 Mar;25(3):357-9.

36. Knaus H, Abbushi A, Hoffmann KT, Schwarz K, Haberl H, Thomale UW. Measurements of burr-hole localization for endoscopic procedures in the third ventricle in children. Childs Nervous System. 2009 Mar;25(3):293-9.

37. Sandberg DI. Endoscopic management of hydrocephalus in pediatric patients: a review of indications, techniques, and outcomes. Journal of Child Neurology. 2008 May;23(5):550-60.

38. Nishiyama K, Mori H, Yoshimura J, Fujii Y. Endoscopic fenestration of the third ventricle in the reverse direction. Childs Nervous System. 2008 Apr;24(4):507-8.

39. Harris AE, Hadjipanayis CG, Lunsford LD, Lunsford AK, Kassam AB. Microsurgical removal of intraventricular lesions using endoscopic visualization and stereotactic guidance. [Reprint in Neurosurgery. 2008 Feb;62 Suppl 2:622-9; PMID: 18596442]. Neurosurgery. 2005 Jan;56(1 Suppl):125-32; discussion -32.

40. Brockmeyer D. Techniques of endoscopic third ventriculostomy. Neurosurgery Clinics of North America. 2004 Jan;15(1):51-9.

41. Costa Val JA, Scaldaferri PM, Furtado LM. de Souza Baptista G. Third ventriculostomy in infants younger than 1 year old. Childs Nervous System. 2012 Aug;28(8):1233-5.

42. Kulkarni AV, Drake JM, Kestle JRW, et al. Predicting who will benefit from endoscopic third ventriculostomy compared with shunt insertion in childhood hydrocephalus using the ETV Success Score. Journal of Neurosurgery. 2010 Oct; Pediatrics, 6(4):310-5.

43. Garcia LG, Lopez BR, Botella GI, et al. Endoscopic Third Ventriculostomy Success Score (ETVSS) predicting success in a series of 50 pediatric patients. Are the outcomes of our patients predictable? Childs Nervous System. 2012 Aug;28(8):1157-62.

44. Kulkarni AV, Riva-Cambrin J, Browd SR. Use of the ETV Success Score to explain the variation in reported endoscopic third ventriculostomy success rates among published case series of childhood hydrocephalus. Journal of Neurosurgery Pediatrics. $2011 \mathrm{Feb} ; 7(2): 143-6$.

45. Ros B, Romero L, Ibanez G, et al. Success criteria in pediatric neuroendoscopic procedures. Proposal for classification of results after 67 operations. Childs Nervous System. 2012 May;28 (5):691-7.

46. Javadpour M, Mallucci C. The role of neuroendoscopy in the management of tectal gliomas. Childs Nervous System. 2004 Nov;20(11-12):852-7.

47. Farin A, Aryan HE, Ozgur BM, Parsa AT, Levy ML. Endoscopic third ventriculostomy. Journal of Clinical Neuroscience. 2006 Aug;13(7):763-70.
48. El-Ghandour NMF. Endoscopic cyst fenestration in the treatment of uniloculated hydrocephalus in children. Journal of Neurosurgery Pediatrics. 2013 Apr;11(4):402-9.

49. El-Ghandour NMF. Endoscopic cyst fenestration in the treatment of multiloculated hydrocephalus in children. Journal of Neurosurgery. 2008 Mar;Pediatrics, 1(3):217-22.

50. Oi S, Abbott R. Loculated ventricles and isolated compartments in hydrocephalus: their pathophysiology and the efficacy of neuroendoscopic surgery. Neurosurgery Clinics of North America. 2004 Jan;15(1):77-87.

51. Bhatia R, Tahir M, Chandler CL. The management of hydrocephalus in children with posterior fossa tumours: the role of pre-resectional endoscopic third ventriculostomy. Pediatric Neurosurgery. 2009;45 (3):186-91.

52. Hailong F, Guangfu $H$, Haibin $T$, et al. Endoscopic third ventriculostomy in the management of communicating hydrocephalus: a preliminary study. Journal of Neurosurgery. 2008 Nov;109(5):923-30.

53. Gangemi M, Maiuri F, Buonamassa S, Colella G. de Divitiis E. Endoscopic third ventriculostomy in idiopathic normal pressure hydrocephalus. Neurosurgery. 2004 Jul;55(1):129-34; discussion 34.

54. Paidakakos N, Borgarello S, Naddeo M. Indications for endoscopic third ventriculostomy in normal pressure hydrocephalus. Acta Neurochirurgica - Supplement. 2012;113:123-7.

55. Pinto FCG, Saad F, MFd Oliveira, et al. Role of endoscopic third ventriculostomy and ventriculoperitoneal shunt in idiopathic normal pressure hydrocephalus: preliminary results of a randomized clinical trial. Neurosurgery. 2013 May;72(5):845-53; discussion 53-4.

56. Chan AK, McGovern RA, Zacharia BE, et al. Inferior Short-Term Safety Profile of Endoscopic Third Ventriculostomy as Compared to Ventriculoperitoneal Shunt Placement for Idiopathic Normal Pressure Hydrocephalus: A Population-Based Study. Neurosurgery. 2013 Aug; 5.

57. Hamilton MG, Price AV. Syndrome of inappropriately low-pressure acute hydrocephalus (SILPAH). Acta Neurochirurgica Supplement. 2012;113:155-9.

58. Tisell M, Almstrom O, Stephensen H, Tullberg M, Wikkelso C. How effective is endoscopic third ventriculostomy in treating adult hydrocephalus caused by primary aqueductal stenosis? Neurosurgery. 2000 Jan;46(1):104-10; discussion 10-1.

59. Ogiwara H, Dipatri AJ, Jr., Alden TD, Bowman RM, Tomita T. Endoscopic third ventriculostomy for obstructive hydrocephalus in children younger than 6 months of age. Childs Nervous System. 2010 Mar;26(3):343-7.

60. Lipina R, Reguli S, Dolezilov, et al. Endoscopic third ventriculostomy for obstructive hydrocephalus in children younger than 6 months of age: is it a first-choice method? Childs Nervous System. 2008 Sep;24(9):1021-7.

61. Baldauf J, Oertel J, Gaab MR, et al. Endoscopic third ventriculostomy in children younger than 2 years of age. Childs Nervous System. 2007 Jun;23(6):623-6.

62. Drake JM, Kulkarni AV, Kestle J. Endoscopic third ventriculostomy versus ventriculoperitoneal shunt in pediatric patients: a decision analysis. Childs Nervous System. 2009 Apr;25(4):467-72.

63. Elgamal EA, El-Dawlatly A-A, Murshid WR, El-Watidy SMF, Jamjoom ZA-AB. Endoscopic third ventriculostomy for hydrocephalus in children younger than 1 year of age. Childs Nervous System. 2011 Jan;27(1):111-6.

64. Bouras T, Sgouros S. Complications of endoscopic third ventriculostomy. Journal of Neurosurgery Pediatrics. 2011 Jun;7 (6):643-9.

65. Jenkinson MD, Hayhurst C, Al-Jumaily M, Kandasamy J, Clark S, Mallucci CL. The role of endoscopic third ventriculostomy in adult patients with hydrocephalus. Journal of Neurosurgery. 2009 May;110(5):861-6.

66. Egger D, Balmer B, Altermatt S, Meuli M. Third ventriculostomy in a single pediatric surgical unit. Childs Nervous System. 2010 Jan;26(1):93-9.

67. Brockmeyer D, Abtin K, Carey L, Walker ML. Endoscopic third ventriculostomy: an outcome analysis. Pediatric Neurosurgery. 1998 May;28(5):236-40. 
68. Ersahin Y, Arslan D. Complications of endoscopic third ventriculostomy. Childs Nervous System. 2008 Aug;24(8):943-8.

69. Rekate HL. Selecting patients for endoscopic third ventriculostomy. Neurosurgery Clinics of North America. 2004 Jan;15(1):39-49.

70. McMillen JL, Vonau M, Wood MJ. Pinless frameless electromagnetic image-guided neuroendoscopy in children. Childs Nervous System. 2010 Jul;26(7):871-8.

71. Sangra M, Clark S, Hayhurst C, Mallucci C. Electromagneticguided neuroendoscopy in the pediatric population. Journal of Neurosurgery. 2009 Apr;Pediatrics, 3(4):325-30.

72. Rohde V, Behm T, Ludwig H, Wachter D. The role of neuronavigation in intracranial endoscopic procedures. Neurosurgical Review. 2012 Jul;35(3):351-8.

73. Choi KY, Seo BR, Kim JH, Kim SH, Kim TS, Lee JK. The usefulness of electromagnetic neuronavigation in the pediatric neuroendoscopic surgery. Journal of Korean Neurosurgical Society. 2013 Mar;53(3):161-6.

74. Najjar MW, Azzam NI, Baghdadi TS, Turkmani AH, Skaf G. Endoscopy in the management of intra-ventricular lesions: preliminary experience in the Middle East. Clinical Neurology \& Neurosurgery. 2010, Jan; 112(1):17-22.

75. Ahmad F, Sandberg DI. Endoscopic management of intraventricular brain tumors in pediatric patients: a review of indications, techniques, and outcomes. Journal of Child Neurology. 2010 Mar;25(3):359-67.

76. Hanada T, Oyoshi T, Hirano H, Arita K. Metastatic pineal tumors treated by neuroendoscopic surgery-two case reports. Neurologia Medico-Chirurgica. 2010;50(3):232-6.

77. Badie B, Brooks N, Souweidane MM. Endoscopic and minimally invasive microsurgical approaches for treating brain tumor patients. J Neurooncol. 2004 Aug-Sep;69(1-3):209-19.

78. Teo C, Nakaji P. Neuro-oncologic applications of endoscopy. Neurosurgery Clinics of North America. 2004 Jan;15(1):89-103.

79. Luther N, Cohen A, Souweidane MM. Hemorrhagic sequelae from intracranial neuroendoscopic procedures for intraventricular tumors. Neurosurgical Focus. 2005 Jul; 15;19(1):E9.

80. Souweidane MM. Endoscopic surgery for intraventricular brain tumors in patients without hydrocephalus. [Reprint in Neurosurgery. 2008 Jun;62(6 Suppl 3):1042-8; PMID: 18695524]. Neurosurgery. 2005 Oct;57(4 Suppl):312-8; discussion -8.

81. Tirakotai W, Hellwig D, Bertalanffy H, Riegel T. The role of neuroendoscopy in the management of solid or solid-cystic intra- and periventricular tumours. Childs Nervous System. 2007 Jun;23(6):653-8.

82. Al-Tamimi YZ, Bhargava D, Surash S, et al. Endoscopic biopsy during third ventriculostomy in paediatric pineal region tumours. Childs Nervous System. 2008 Nov;24(11):1323-6.

83. Klimo P Jr., Goumnerova LC. Endoscopic third ventriculocisternostomy for brainstem tumors. Journal of Neurosurgery. 2006 Oct;105(4 Suppl):271-4.

84. O'Brien DF, Hayhurst C, Pizer B, Mallucci CL. Outcomes in patients undergoing single-trajectory endoscopic third ventriculostomy and endoscopic biopsy for midline tumors presenting with obstructive hydrocephalus. Journal of Neurosurgery. 2006 Sep;105(3 Suppl):219-26.

85. Cipri S, Gangemi A, Cafarelli F, et al. Neuroendoscopic management of hydrocephalus secondary to midline and pineal lesions. Journal of Neurosurgical Sciences. 2005 Sep;49(3):97-106.

86. Yurtseven T, Ersahin Y, Demirtas E, et al. Neuroendoscopic biopsy for intraventricular tumors. Minimally Invasive Neurosurgery. 2003 Oct;46(5):293-9.

87. Di Rocco F, Juca CE, Zerah M, Sainte-Rose C. Endoscopic third ventriculostomy and posterior fossa tumors. World Neurosurgery. 2013 Feb;79(2 Suppl):S18.e5-9.

88. Morgenstern PF, Souweidane MM. Pineal region tumors: simultaneous endoscopic third ventriculostomy and tumor biopsy. World Neurosurgery. 2013 Feb;79(2 Suppl):S18.e9-3.

89. Shahinian HK, Ra Y. 527 fully endoscopic resections of vestibular schwannomas. Minimally Invasive Neurosurgery. 2011 Apr;54 (2):61-7.

90. Wong T-T, Chen H-H, Liang M-L, Yen Y-S, Chang F-C. Neuroendoscopy in the management of pineal tumors. Childs Nervous System. 2011 Jun;27(6):949-59.
91. Oppido PA, Fiorindi A, Benvenuti L, et al. Neuroendoscopic biopsy of ventricular tumors: a multicentric experience. Neurosurgical Focus. 2011 Apr;30(4):E2.

92. Tirakotai W, Riegel T, Stiegel A, et al. Peri-operative quality of life assessment in endoscopically treated patients with pineal region tumours. Childs Nervous System. 2007 Jun;23(6):659-63.

93. Constantini S, Mohanty A, Zymberg S, et al. Safety and diagnostic accuracy of neuroendoscopic biopsies: an international multicenter study. Journal of Neurosurgery Pediatrics. 2013 Jun;11(6):704-9.

94. Awaji M, Okamoto K, Nishiyama K. Magnetic resonance cisternography for preoperative evaluation of arachnoid cysts. Neuroradiology. 2007 Sep;49(9):721-6.

95. Pradilla G, Jallo G. Arachnoid cysts: case series and review of the literature. Neurosurgical Focus. 2007;22(2):E7.

96. Oertel JM, Baldauf J, Schroeder HW, et al. Endoscopic cystoventriculostomy for treatment of paraxial arachnoid cysts. Journal of Neurosurgery. 2009 Apr;110(4):792-9.

97. Ersahin Y, Kesikci H. Endoscopic management of quadrigeminal arachnoid cysts. Childs Nervous System. 2009 May;25(5):569-76.

98. Ersahin Y, Kesikci H, Aksen M, Aydin C, Mutluer S. Endoscopic treatment of suprasellar arachnoid cysts. Childs Nervous System. 2008 Sep;24(9):1013-20.

99. Di Rocco F, R James S, Roujeau T, Puget S, Sainte-Rose C, Zerah M. Limits of endoscopic treatment of sylvian arachnoid cysts in children. Childs Nervous System. 2010 Feb;26(2): $155-62$.

100. Huang Q, Wang D, Guo Y, Zhou X, Wang X, Li X. The diagnosis and neuroendoscopic treatment of noncommunicating intracranial arachnoid cysts. Surgical Neurology. 2007 Aug;68(2):149-54; discussion 54.

101. Nowoslawska E, Polis L, Kaniewska D, et al. Neuroendoscopic techniques in the treatment of arachnoid cysts in children and comparison with other operative methods. Childs Nervous System. 2006 Jun;22(6):599-604.

102. Schroeder HWS, Oertel J, Gaab MR. Endoscopic treatment of cerebrospinal fluid pathway obstructions. Neurosurgery. 2007 Feb;60(2 Suppl 1):ONS44-51; discussion ONS-2.

103. Spacca B, Kandasamy J, Mallucci CL, Genitori L. Endoscopic treatment of middle fossa arachnoid cysts: a series of 40 patients treated endoscopically in two centres. Childs Nervous System. 2010 Feb;26(2):163-72.

104. Cinalli G, Peretta P, Spennato P, et al. Neuroendoscopic management of interhemispheric cysts in children. Journal of Neurosurgery. 2006 Sep;105(3 Suppl):194-202.

105. Karabagli H, Etus V. Success of pure neuroendoscopic technique in the treatment of Sylvian arachnoid cysts in children. Childs Nervous System. 2012 Mar;28(3):445-52.

106. Abbott R. The endoscopic management of arachnoidal cysts. Neurosurgery Clinics of North America. 2004 Jan;15(1): 9-17.

107. Charalampaki P, Filippi R, Welschehold S, Perneczky A. Endoscope-assisted removal of colloid cysts of the third ventricle. Neurosurgical Review. 2006 Jan;29(1):72-9.

108. Grondin RT, Hader W, MacRae ME, Hamilton MG. Endoscopic versus microsurgical resection of third ventricle colloid cysts. Canadian Journal of Neurological Sciences. 2007 May;34(2):197-207.

109. Charalampaki P, Filippi R, Welschehold S, Conrad J. Endoscopic and endoscope-assisted neurosurgical treatment of suprasellar arachnoidal cysts (Mickey Mouse cysts). Minimally Invasive Neurosurgery. 2005 Oct;48(5):283-8.

110. Longatti P, Godano U, Gangemi M, et al. Cooperative study by the Italian neuroendoscopy group on the treatment of 61 colloid cysts. [Erratum appears in Childs Nerv Syst. 2006 Oct;22(10):1375]. Childs Nervous System. 2006 Oct;22(10):1263-7.

111. Mishra S, Chandra PS, Suri A, Rajender K, Sharma BS, Mahapatra AK. Endoscopic management of third ventricular colloid cysts: eight years' institutional experience and description of a new technique. Neurology India. 2010 May-Jun;58(3):412-7.

112. Zohdi A, El Kheshin S. Endoscopic approach to colloid cysts. Minimally Invasive Neurosurgery. 2006 Oct;49(5):263-8. 
113. Tamburrini G, D'Angelo L, Paternoster G, Massimi L, Caldarelli M, Di Rocco C. Endoscopic management of intra and paraventricular CSF cysts. Childs Nervous System. 2007 Jun;23(6):645-51.

114. Tirakotai W, Schulte DM, Bauer BL, Bertalanffy H, Hellwig D. Neuroendoscopic surgery of intracranial cysts in adults. Childs Nervous System. 2004 Nov;20(11-12):842-51.

115. Margetis K, Souweidane MM. Endoscopic treatment of intraventricular cystic tumors. World Neurosurgery. 2013 Feb;79(2 Suppl):S19.e1-1.
116. Lewis AI, Crone KR, Taha J, van Loveren HR, Yeh HS, Tew JM, Jr. Surgical resection of third ventricle colloid cysts. Preliminary results comparing transcallosal microsurgery with endoscopy. Journal of Neurosurgery. 1994 Aug;81(2):174-8.

117. Greenlee JDW, Teo C, Ghahreman A, Kwok B. Purely endoscopic resection of colloid cysts. Neurosurgery. 2008 Mar;62 (3 Suppl 1):51-5; discussion 5-6. 